\title{
$1-$ EDITORIAL
}

\section{APELO AOS AUTORES}

\author{
Saul Goldenberg ${ }^{\mathrm{I}}$, Tânia Pereira Morais Fino ${ }^{\mathrm{II}}$ \\ ${ }^{\mathrm{I}}$ Editor Chefe Acta Cirúrgica Brasileira. \\ ${ }^{\text {II }}$ Revisora Acta Cirúrgica Brasileira
}

Esta comunicação é um apelo dirigido aos nossos usuários.

Negligência é falta de apuro, de atenção, desleixo, desmazelo.

Apelo aos nossos colaboradores, que prestem mais atenção às normas e ao estilo da Revista Acta Cirúrgica Brasileira, antes de enviarem os seus artigos, disponível em www.scielo.br/acb (Instruções aos autores).

Em 2006 publicamos carta aos leitores ${ }^{1}$. As desatenções, distrações, descumprimento das normas, desrespeito às convenções nacional [idioma português], internacional [inglês], desconsideração à nomenclatura e terminologia vigentes continuaram a serem cometidos.

Norma regula procedimentos, cumpre regras a fim de se atingir um padrão de excelência. Norma caracteriza disciplina. Normalizar é salutar ${ }^{2}$. A Revista Acta Cirúrgica Brasileira adotou como padrão as recomendações do International Committee of Medical Journal Editors ${ }^{3}$.

\section{Ocorrências frequentes nos artigos enviados à Acta Cirúrgica Brasileira}

Falta de consulta às instruções aos autores que podem ser acessadas em www.scielo.br/acb.

Falta em consultar exemplares recentes da revista para servirem como modelo.

\section{Transferência dos direitos autorais}

Exigência habitualmente não cumprida: Os autores cujos trabalhos forem aceitos para publicação pela revista transferem todos os direitos de reprodução (copyright) a Acta Cirúrgica Brasileira. Uma carta contendo essa declaração deve ser encaminhada junto com o trabalho, assinada por todos os autores. O autor principal assume a responsabilidade de que todos os autores concordaram com o conteúdo do artigo enviado.

Declaração a ser enviada por carta ou e-mail, devidamente assinada:

"Os autores, abaixo assinados, transferem todos os direitos autorais do artigo intitulado "

"á Acta

Cirúrgica Brasileira. Garantem que o artigo é original, não infringe qualquer direito autoral ou direito à propriedade de terceiros, $\underline{\text { não }}$ está em avaliação por outro periódico e não foi previamente publicado. O trabalho foi lido e cada contribuição foi aprovada.” Nome legível e assinatura dos autores.

\section{Preparação do manuscrito}

Os originais devem ser enviados por e-mail (sgolden@terra.com.br) e escritos no idioma inglês. A Revista tem preferência pelo Word for Windows 7.0.

Os originais devem incluir: título do artigo nos idiomas inglês e português.

\section{Titulação acadêmica dos autores}

Vínculo institucional e titulação acadêmica, no idioma inglês, conforme norma da revista disponível em www.scielo.br/acb ${ }^{4}$.

A Revista Acta Cirúrgica Brasileira segue "Ethical Considerations in the Conduct and Reporting of Research: Authorship and Contributorship disponível em www.icmje.org $\underline{3}$ que considera todos os participantes do artigo como autores. Autores são considerados aqueles que têm efetiva contribuição intelectual e científica na realização do trabalho.

Identificar o autor principal. O autor principal é o responsável pela integridade do artigo, como um todo, não necessariamente ser o primeiro autor. Deve informar a contribuição de cada autor nominado no artigo submetido à publicação e encaminhar lista com a assinatura de cada autor. do artigo;

1. Definir o autor responsável pela concepção e delineamento do estudo e responsável pelo conteúdo intelectual e científico

2. Aquisição dos dados;

3. Interpretação dos dados; 
4. Redação do manuscrito;

5. Revisão crítica;

6. Análise estatística;

7. Se aluno de Programa de Pós-graduação, informar se o artigo é parte de tese, nível mestrado, doutorado ou pós-doutorado e nome do Professor Orientador.

Pessoas que não cumprem estes requisitos e que tiveram participação puramente técnica (ato operatório, revisão bibliográfica, chefes de departamento, serviços ou financiados) devem ser listados nos agradecimentos. Mencionar o responsável pela versão para o idioma inglês.

Abstract/Resumo Devem ser estruturados. Aparecem descuidos no que se refere aos idiomas e no conteúdo informativo.

Descritores em Ciências da Saúde

Os Key Words/Descritores são essenciais para a acessibilidade e recuperação dos artigos. O DeCS [Descritores em Ciências da Saúde] facilita o acesso à informação e guia os usuários na localização e seleção da informação científica. Termos, nos descritores, que não estão no DeCS impedem a localização do artigo. Portanto, se os autores desejam que seus artigos sejam encontrados torna-se imperioso pesquisar no DeCS os termos corretos: acessar http://decs.bvs.br ${ }^{5}$. a seguir Consulta ao DeCS e por fim Consulta por Palavra, nos idiomas inglês, espanhol e português.

Cumprir as normas referente a: Introdução, Métodos, Resultados, Discussão, Conclusão e Referências (Agradecimento, se houver). Não se aceita unir capítulos, como "resultados e discussão" ou "resultados e conclusões"

\section{Estatística}

Descrever os métodos estatísticos com pormenor e fornecer referências para os procedimentos consagrados.

\section{Ética}

A investigação em animais deve ser submetida à Comissão de Ética no Uso de Animais (CEUA) cumprindo a Lei Federal $n^{\circ}$ 11.794, de 8 de outubro de 2008, http://www.planalto.gov.br/ccivil_03/_Ato2007-2010/2008/Lei/L11794.htm e o Decreto n ${ }^{\circ}$ 6.689, de 15 de julho de 2009 que regulamentada a Lei no 11.794, disponível em: http://www.planalto.gov.br/ccivil_03/_Ato2007-2010/2009/ Decreto/D6899.htm.

Os autores estrangeiros devem seguir o CIOMS (Council for International Organization of Medical Sciences) ethical code for animal experimentation (WHO Chronicle 1985;39(2):51-6)

Pesquisas em seres humanos devem ser aprovadas pelo Comitê de Ética da Instituição onde o trabalho foi realizado, cumprindo Resolução n. 196/96 do Conselho Nacional de Saúde.

Enviar certificado da Comissão de Ética, assinada, de aprovação da pesquisa.

\section{Tabelas e figuras}

Os autores não indicam, no texto, os locais das tabelas e das figuras, com as respectivas legendas. Muitas vezes as legendas não explicam o que as figuras mostram, dificultando o entendimento do leitor. As tabelas devem ter o enunciado acima e as figuras devem ter as legendas, abaixo. Acrescente-se que a falta de qualidade das ilustrações, prejudica a reprodução. Enviar as figuras coloridas.

Negligência no cumprimento das normas referentes à Nomenclatura/Terminologia ${ }^{6}$.

\section{Conclusão}

Deve ser clara, concisa e precisa. Sem comentários.

Os autores enviam os artigos sem a devida e cuidadosa revisão. As agências como a CAPES, CNPq, FAPESP, SciELO, MEDLINE, EXCERPTA MEDICA, ISI e leitores exigentes avaliam os artigos publicados e observam "com lente de aumento" a forma, o conteúdo científico e o esmero na padronização das normas da publicação.

\section{Referências}

Cumprir as normas do ICMJE.

É frequente o descuido no levantamento bibliográfico. É frequente a não citação de autores nacionais, inclusive de artigos da própria revista publicados na SciELO e falta de pesquisa no Medline/PubMed.

As referências devem ser numeradas consecutivamente na ordem em que foram mencionadas a primeira vez no texto, com respectivo número sobrescrito.

Os nomes de todos os autores devem ser citados nas referências (et al. não é aceito). Não são aceitas referências a resumos, comunicação pessoal ou qualquer outra fonte não indexada. Livros texto e teses não são aceitos, pois não estão indexados. Referir artigo publicado em periódico indexado, pertinente ao tema. 
Os títulos dos periódicos devem ser abreviados de acordo com o estilo usado na lista de revistas indexadas no MEDLINE colocada pela NLM no Web site da Biblioteca.

Declaração do Conflito de interesse (a fim de cumprir a Resolução do Conselho Federal de Medicina n.1595/2000, que veda "artigos, mensagens e materiais promocionais de produtos ou equipamentos de uso na área médica").

$\mathrm{O}$ autor deve informar a(s) fonte(s) de financiamento do trabalho de agências de fomento.

Os dados na correspondência deverão ser do autor responsável.

É do mútuo interesse do editor da revista e dos autores manterem o padrão da revista.

Consultar www.scielo.br/acb e exemplar recente da revista a fim de seguir as normas e o estilo adotados.

Dúvidas, perguntas e esclarecimentos podem ser enviadas para sgolden@terra.com.br ou para o Tel: (11)3287-8814.

\section{Referências}

1. Goldenberg S, Fino TPM. Carta aos autores. Acta Cir Bras. 2006;21(6):360-1.

2. Goldenberg S. Normalizar é salutar. Acta Cir Bras. 2000;15(2):79.

3. Uniform Requirements for Manuscripts Submitted to Biomedical Journals: Writing and Editing for Biomedical Publications. Available from www.icmje.org

4. Goldenberg S, Matone J. Academic degrees. Standardization in English language. Acta Cir Bras. 2006;21(2):60.

5. Descritores em Ciências da Saúde (DeCS). Disponível em http:// decs.bvs.br

6. Terminologia anatômica. São Paulo: Ed. Manole; 2001. 